\title{
The Development of Algo-Heuristic Model: To Improve Student Learning Acquisition in Statistics at Elementary School Teacher Education
}

\author{
Rufi'i
}

\begin{abstract}
The purpose of this study is to test the effectiveness of algo-heuristic models in improving the students' academic achievement of elementary school teacher education. This study consists of: (1) the first phase of testing (small group) carried out by instructional design and expert statistical learning, (2) the second phase of testing (large group) conducted by the course lecturer, and ( 3 ) the effectiveness of testing conducted on students. Procedures focus on the development of an evaluation of algo-heuristic theory. Evaluation consists of three stages. Stage 1, to test the theoretical product quality Expert test, subjects (instructional design and quality) are asked to rate the acceptability of algo-heuristics as to usefulness, feasibility and accuracy before being tested on students. Stage 2, test to a small group of Elementary School Teacher Education's lecturers. This means that before the students are presented with algo-heuristics the lecturers are first equipped with an algo-heuristic guide. The goal is for teachers to understand the concept. Stage 3, large group testing to determine the effectiveness of the implementation of the algo-heuristic model to improve the learning of statistics students using pre-experimental research. The pre-test mean score is 61.43 . The post-test mean score is 69.48. There is a difference between the scores of 8.05. This shows a relative increase of $13.1 \%$. T-test analysis results give a score of $\mathbf{- 5 . 1 1 1}$ with a probability of 0.000. Score statistics show a significant increase and the performance statistics indicate a rising trend. This indicates an adequate statistical basis for algo-heuristic learning to be implemented.
\end{abstract}

Index Terms-Academic achievement, acquisition of statistical learning, algo-heuristic, student's evaluation.

\section{INTRODUCTION}

The demands of studying in universities require students to be able to improve their statistical gains by mastering learning theories relating to quickly completing the processing of information they receive, so they are ready to enter the real world of work after completing studies. From the initial research of the students of Elementary School Teacher Education (Pendidikan Guru Sekolah Dasar/PGSD) and the University of PGRI AdiBuana Surabaya, 28 students $(66.7 \%)$ agree that motivation is important in gaining knowledge and skills. Six students $(15.4 \%)$ are in the low learning motivation category. 19 students $(48.7 \%)$ are in the moderate learning motivation category and 14 students

Manuscript received February 26, 2014; revised July 22, 2014. This research was supported by Directorate of Higher Education, Ministry of Education and Culture of Indonesia.

Rufi'i is with the Postgraduate program, Instructional Technology Study Program, University PGRI Adi Buana Surabaya, Indonesia (e-mail rufii.unipa2013@gmail.com).
(35.9\%) are in the high learning motivation category. With regard to student independence, five students (12.8\%) are in the low category.

Statistics shows that learning still generally relies on lectures. Such learning usually pays less attention to individual students. Every individual is in a different category. [1] Davies (1984) states that the differences are: 1) skills and abilities, 2) knowledge, skills, and attitudes, 3) personality and learning style, and 4) age and experience. [2] Charles (1980) on individual differences states that they are 1) intellectual development, 2) the ability to use symbols or languages, 3) background experience, 4) learning style, 5) personality and 6) an overview of themselves.

To overcome the obstacles in conventional teaching, learning strategies should be developed. [3] Landa (1987) who noticed differences in the abilities of students suggests that algo-heuristic problem solving can facilitate student learning. He states that the purpose is to be able to teach the students effectively about how to apply knowledge and solve problems accordingly. Algorithms can streamline the process in learning.

Furthermore, [4] Landa (1999) states that the greater the differences or discrepancies between the number of variations objectively necessary and the number of actual variations available, the greater the likelihood that a) the generalization that formed in the thoughts of students would not be matched and as a result b) the average level of inaccurate concepts based on the generalization would be very high.

\section{LITERATURE REVIEW}

Based on the research problem, the discussion of related theories to the algo-heuristic in the study of Elementary Teacher Training Education students are described as follows. [5] Landa (1974) gives an example, one can develop knowledge of a student of some chemical processes, but knowledge does not automatically generate a skill associated with this process. Lose some knowledge skills treated prior knowledge as a prerequisite, but knowledge does not have the same value with skill. Each skill is an ability to apply the knowledge and skills that demonstrate the specific action on the knowledge and/or object.

Ref. [6] Landa (1976), the characteristic shape of the learning algo-heuristic theory is the need for analysis of the implementation, in particular the implementation of cognitive to some basic level of known how to put them together in a series of lessons.

Ref. [7] Landa (1983), a process that consists of a series of 
relatively basic operations that are performed in a regular and uniform in a condition that gives an explanation to resolve the problems of a particular class is an algorithmic process. Further, [7] Landa (1983) states Algorithmic be designed and used primarily in the field of mathematics, while [8] Hembree and Marsh (1994) which states that the algorithmic procedure to establish rules and procedures to guide the learner's problem solving to find a solution. However, [4] Landa (1999) states that the greater the difference/incompatibility between the number of variations is objectively necessary and the amount of actual variations available, the greater the likelihood that (a) the generalization that formed in the minds of learners will be no match and as a result, and (b) the average level concepts based on inaccurate generalizations will be very high. [4] Landa (1999) makes the formation into a formation that is well planned and well organized learning process, thus guaranteeing the high quality of the development of mental abilities as a result of a collaboration.

Ref. [9] Gumadi, Gribble, Ratnasamy, Shenker, and Stoica (2003) introduce new algorithms. This learning can be expanded into a class of geometric routing, circuit theory can be derived from a variety of simulation results, and the result of the routing geometry (in particular, is the equation - the deficiencies of the geometry) can be observed that the first step of a study of routing algorithms are more basic / fundamental.

Ref. [10] Kuhn, Fabian, Roger, and Aaron (2003) suggest a new algorithm namely the geometric ad-hoc routing algorithm combining greedy and face routing (GOAFR). It has been proven that GOAFR is a straight line that best approached the curve but does not cut it, the 'ratio' which is competitive with the shortest distance. In simulation theory is applied to identify tissue density in critical areas where generally the shortest distance between 'source' and 'destination' which is significantly larger than the Euclidean distance, the concentrations of forming a clear challenge for any routing algorithm. The above simulations have shown that GOAFR not only provides insurance against the worst cases, but also the efficiency of the usual cases. GOAFR is also for ordinary cases in which large networks using GPSR algorithm.

Ref. [11] Heeren, Jagadish, and Pitt (2003) find a general technique or in part in the selection index that is expected to minimize the use of the display space, and also indicates that it is necessary to obtain the algorithm. In previous research has shown that the relaxation of space (simplification of data) is an important model used is a simplification of the one involving intersection more natural, which at times can then be done along with other fashion models. [12] Chirkova, Rada, and Chen (2003) find that the results for the complex workload on conjunctive (related) questions are clearly different depending on whether the question has attachment to one another. Furthermore, an algorithm is developed to obtain an optimal solution and a study in order to become an efficient algorithm.

Ref. [13] Cagalj, Jean, and Christian (2004) have found that, first, study the complexity of the problem. Discuss two forms displayed by a special graph: a graph that is common/general and a graph in Euclidean space (geometric case). Second, development of algorithms, known as EWMA
(Embedded Wireless Multicast Advantage) indicates that in this algorithm there is one important proposals contained in the list of theories. Moreover described distribution of EMWA complete version is a form that can be recognized by other experts regarding the importance and challenges, which it cannot be found in the theory.

Ref. [14] Ballarin (2004) shows limited programming using algebraic system that can be applied to systems of parametric equations linier. According to the version of algorithm computing Gaussian calculations, computational calculations and completion of the parametric determination can be used as a basis for determining the parametric linear calculation. [15] Hutchinson, John., Gigerenzer, and Gerd (2005) prove that mathematically, the decision taken by the heuristic thinking patterns are effective. In humans algorithmic approach which is the basis for managing the process of thinking that spawned sort cognitive capabilities. The ability to adapt to the environment based on rationalistic thinking patterns using mathematical calculations based heuristic thinking patterns. While the biological aspects of life experience who also bore an important part of the overall decision making process. Biological effect of psychological look good attitudes and behavior of animals and humans in the ability of preparing a series of considerations based on instinct.

Ref. [16] Leguay, Jeremi, East, and Vania (2005) find the compute capability performance conductor that serves as a transport stream flows knot used concepts track record algorithmic calculated. The calculation includes the average delay time delivery of data flows and the slowness of delivery is based on the length of the travel route data. Formulation MobySpace concept definition and the use of the trace tracking scheme using calculations based on the height of formality Euclian dimensional space (virtual space) that are built using the current node mobility patterns. In the future development of virtual information flow (data flow) Internet data network can be utilized for the improvement of the frequency of contact wearer's wireless network (LAN).

Ref. [17] Syarafi, Bassem, Dirk, and Paul (2005) show the recommended heuristic concept, managed to work well in both low and high -capacity devices. This raises a positive effect on the performance of the concept algorithm applied, e.g. for software Maxminer and Apriori B and shows a consistency of the NDI - sort algorithm representation. The findings of these studies support the development of research findings. Algo-heuristic learning strategy is a process of thinking and making that automatically process in a step by step that provides an explanation after a step has been mastered that should be applied along with all the steps that have been there before in algorithm. Strategy learning algo-heuristic can be applied by means students need to know the composition and structure of cognitive operational processes belonging to the application of knowledge. One should know the composition and arrangement of the mechanism of thinking about the process of moving (from science to application). Lecturers have to look at the course material of Statistics, and then the problem is algorithmic and heuristic. Problem solvers who are experts and professors are often not sensitive or sensitized but not fully the processes that they show the real, so when you are teaching; it cannot provide this understanding to the students. This discovery 
process is often complex and the learners are not taught how to find and heuristic algorithmic normally, only some of them can make a discovery (problem solving) spontaneously.

Apart from the concept of algorithm, [18] Heong, et al (2011) conducted a study on technical education students' perceptions of Marzano's HoTS levels in their academic and daily lives. The result of the study showed that there was a very low positive relationship between the level of Marzano's HoTS with gender, academic achievement and socio economic status. Further, there is no significant difference in thinking levels between male and female students; neither among their academic achievement or socio economic status. Therefore, students should be assisted to acquire HoTS; either through the conventional teaching and learning environment or a self-instructional, individualized manual.

Those who fail to find that the decision to have problems in learning and problem solving and being unsuccessful in achieving what is expected. Requirements of algo-heuristic generally cover (1) the main purpose of algorithmic than formula-based learning algorithm to be one of the learning algorithm. The formula of algorithm shows an educational function that is more sensitive to operational. Students of algorithms that make them easier and faster to perform generalization and learning process. If the goal of the learning designer or lecturer is to develop the students themselves regarding sensitivity to process algorithms and their generalizations sooner, they should use the formula algorithms to teach algorithmic process. If one's goal is more pragmatic and someone wants to develop only one specific cognitive skill, it would probably make more sense to opt for not using algorithm formula to teach algorithmic process, (2) knowledge of the algorithmic formula is not important for the ability to solve problems and make decisions only mastery of algorithmic process. If participants are devoted to learning is that students do not need to communicate on the ability of other students, and then the designer may only teach the process of learning algorithms or may decide to teach algorithmic formula well. If the student is intended that students will be required to communicate the skills they have learned on the other, then the students should be taught about the formula., (3) both the algorithms and formulas that can be given to the student or the student can be delivered to find it. The discovery of self- education is more valuable, but it requires a lot of time., (4) both the formula and the algorithmic process can be introduced to the students separately, stage by stage, or they can be displayed on the student as a whole., (5) without of whether integral or sequential method that has been used, the lecturer should consider as a special education goals and tasks to facilitate the teaching and learning process algorithmic operations., (6) all the clues lead to the formation and identification of learning algorithms as a concept in a discipline, but the same can be applied to other learning concepts., and (7) as a system of concepts and cognitive operations for one subject is being set up at each stage of learning is important to establish the relationship between the disciplines (inter-disciplinary) between knowledge and operational systems development between each of these disciplines, (Rufi'i, 2010) [19].

\section{RESEARCH METHODS}

\section{A. Development Model}

Application of algo-heuristic models adopted for instructional systems development model of Dick and Carey on the grounds that software developers in the field of education and teaching should use the model used by experts in the field of education (Dick \& Carey, 2001) [20]. The instructional model components of Dick \& Carey (2001) [20] are to: 1) identify the purpose of teaching, 2) analyze teaching, 3) identify entry behaviors, 4) formulate performance, 5) develop gains of standard reference tests, 6) develop teaching strategies, 7) develop and establish modules or teaching guides, 8) design and carry out formative assessment, 9) revise teaching (algo-heuristic) and 10) develop and conduct summative evaluation. Further research for the benefit of a modified Dick \& Carey model show the following scheme.

\section{B. The Development Procedures}

The development of algo-heuristic activities focused on the evaluation of its implementation. Evaluation activities consisted of three stages, 1) testing the theoretical product quality (expert test); 2) small group testing; and 3) large group testing.

First phase Testing (Test Expert Content and Learning Design Expert) Dick \& Carey (2001), [21] suggested three stages of trials designed to assess teaching development in order to become more effective. They were 1) expert assessment, 2) small group (faculty) assessment, and 3) large group (student) assessment. Design expert testing is intended to assess the application of the algo-heuristics and will be used to establish its acceptability. The goal is to find the weaknesses in the algo-heuristic models. The assessment is carried out by experts in instructional design on the subject of statistics. Acceptable test results produce products that have been revised and are used to test the effectiveness of learning materials in the model.

Subject matter experts testing product content areas are experts in statistics, while experts in the field of instructional design products are experts in the science of learning technology. Experts for the test phase are chosen using the following criteria: 1) a degree in the subject matter, 2) an expert in the field of statistics, and 3) experience or research in the field of expertise. Expert test subjects (instructional design and content) were asked to rate the acceptability of algo-heuristics in the qualities of usability, feasibility and accuracy of the algo-heuristics before they were tested on students. Assessment of the manual algo-heuristics was performed by statisticians and experts in instructional design. The questionnaire as to validation and attractiveness of algo-heuristics was made by an expert in the design of learning technology.

The Small Test Group. The goal of this stage is the trial of $P G S D$ lecturers. Before the student is instructed in algo-heuristics the lecturer is equipped with a guide. The aim is that teachers understand the stages of algo-heuristics.

The Large Test Group. Activities in this phase determine the effectiveness of the algo-heuristic model in improving gains in student learning. The target group is the students of PGSD PGRI Adi Buana University of Surabaya. 


\section{RESEARCH FINDINGS}

Results of the validation performed by expert in instructional design are 1) the need to use the student as the subject of a study, 2) consistency in terms (learner not replaced by student), 3) a description that links the use of teaching materials as learning resources with learning syntax, 4) MFI/CGC needs to be stated explicitly in the syntax, 5) the term syntax is enough alone (Arend, 1997) [21] .or strategy (Reigelth) [23], and 6) assessment, which describes the activities undertaken by the students to work on the problems, reports on the results of work, and MGIs using relevant instruments.

\section{A. Expert Content}

The subject matter experts provide some assessment, suggestions, and comments to the perfection of the algo-heuristic model development. In general, experts assess the content of the teaching materials for learning statistics consisting of 1) statistical concepts, 2) establishment of frequency distribution tables and measures of central tendency, 3) population and sample normal distribution, 4) hypothesis testing, 5) chi squared test suitability and independence test (contingency), 6) correlation, linear regression, multiple regression, 7) analysis of variance, and 8) non-parametric tests.

According to the expert assess the content, the design of teaching materials should 1) consider student worksheet tailored to the data in the field, 2) include a list of tables such as " $t$ " and " $r ", 3)$ correct the typing errors. The results of the expert assessment show that the development of algo-heuristic teaching models can be further developed. To improve the quality of content and package, procedures still need to be revised.

The results obtained from assessment by subject experts and instructional design experts on the usability of algo-heuristic models show scores of 26 and 27. Thus, the development of teaching materials in these models should be implemented further.

\section{B. Development Feasibility Aspects of the Algo-Heuristic Model}

Indicators show that the feasibility of teaching materials in the algo-heuristic model are practical and effective.Both experts said that a large amount of time is required to implement the learning through this model. However, both experts agree that the amount of time required will be known only after the study is done. In regards to the cost of developing algo-heuristic models, both experts stated that the costs would be quite large. In other words, in terms of manpower, development of the model is effective, but in terms of cost and time, it is less effective. Each group should ideally be able to work on a task.

It can be seen that both of the expert assessments of the feasibility aspects of the development of algo-heuristic models provide a high score, the average scores by the two experts was 32 . According to the eligibility criteria it can be concluded that the teaching materials to be used as a supplement in the development of algo-heuristic models meet the criteria for their use. Accuracy of Algo-Heuristic Model Development Indicators that are used to show the accuracy of the model in the development of teaching materials are object accuracy, precision formulated objectives, and accuracy of procedure.

Results of expert assessment in view of teaching materials in the development of algo-heuristic models in regards to accuracy are presented in Table I. It shows that both experts judge the accuracy aspect of teaching materials in the algo-heuristic model with a high score, an average total score of 32. Thus, it can be concluded that the teaching materials developed in this model include the appropriate criteria. As a result it can be developed further.

\section{Qualitative Data Expert Assessment on Product Development}

The instructional design and content experts generally recommend that the package should consider writing accuracy (grammar and typographical errors) and simplification of the language, so that students easily understand the intent in the development of algo-heuristic models 1) Instructional design experts recommend that every subject should truly reflect a collaborative learning setting, be more independent of instructors and train students in solving problems, and 2) Aspects of language should be key to achievement of training objectives. Training is suggested in the use of raw language. Once expert training is completed, these components should be revised and used as the basis for refinement of model development prior to field testing of small groups.

\section{Second Stage Assessment Data (Small Group/Lecturers)}

The revised package will serve as the basis for determining the acceptability of prototype materials in development of algo-heuristic models to be tested in a larger group. Data obtained from the second phase is presented below.

\section{1) User data subject assessment products}

Data subject assessments of prospective users are qualitative and quantitative. Qualitative data includes usability, feasibility and precision of materials. Quantitative data includes the first two and accuracy of teaching material.

\section{2) Discussion with subject trainer}

The discussions attempted to determine the acceptability of the package intended for students. Based on these discussions, the feedback obtained from the users (lecturers) is as follows.

1) In general, the teaching material is clear and understandable to students, because it contained materials that students need to improve academic capabilities, and can propel the initiative to develop algo-heuristic models.

2) Many tasks and examples are given to encourage students to undertake the development of models.

3) The material is quite interesting and attracts the attention of students.

\section{E. Quantitative data Lecturer (Outcome Assessment Questionnaires)-Usability Aspects of the Algo-Heuristic Model Development}

According to the assessment criteria on the usability aspect as seen in the above provisions, it is based on the results of user assessment products (3 lecturers) with a total score of each 23, 22 and 21. So that it can be concluded that the 
development of algo-heuristic models are included in the criteria. Thus the algo-heuristic model development can be proceeded.

\section{F. Feasibility Aspects of Algo-Heuristic Model Development}

Product user assessment results (3 lecturers) of algo-heuristic models show that users provide an assessment on the feasibility of developing models of algo-heuristic with which the feasible score. Product user assessment results (3 lecturers) with a total score of respectively 27, 27 and 25. It can be concluded that the development of algo-heuristic models for students is included in the criteria.

\section{G. The Accuracy Aspects of Algo-Heuristic Model Development}

Assessment results show that users of the product (3 lecturers) pass judgment on the accuracy aspect of the development of algo-heuristic models. Results of 9 item questionnaire on aspects of this accuracy, the cumulative rate of the average scores given by the three users of the product ( 3 lecturers) to reach a total score of 27, 27 and 25. According to the users of the product based on the assessment results ( 3 teachers), it can be concluded that the development of algo-heuristic models for students are included in the appropriate criteria. It means that the substance of the algo-heuristic model of development that has been developed to meet the criteria, so it can be developed further.

\section{H. Test Data Observation of a Small Group}

Observations by the three lecturers revealed the following. First lecturer: Generally all the procedures that have been given to the lecturers have been understood, yet it is not so in practice. In giving instructions, teachers have to do it exactly as shown. Second lecturer: Similar to the first, teachers have to understand the model, and there are still some things that need to be addressed: the provision of instruction, as it appears the teachers pay less attention to time and the instructions given were too long. It appeared that the teachers were less able to provide clear examples according to the subject. Third lecturer: Similar to the first and second. The third also understood the procedures that were discussed.

\section{Third Stage Assessment Data}

To obtain data from the development of an algo-heuristic model for students is by performing an initial and a final test using a statistical test instrument. The subjects of the algo-heuristic model implementation were 42 students. The model development consisted of eight subjects: 1) statistical concepts, 2) establishment of frequency distribution tables and measures of central tendency, 3) population and sample normal distribution, 4) hypothesis testing, 5) chi squared test match and freedom test (contingency), 6) correlation, linear regression, multiple regression, 7) analysis of variance, and 8) non-parametric test. To assess the success of the implementation pre and post tests were given. Learning sessions lasted for 10 weeks. This was based on the consideration that with intense learning this is sufficient time and that after eight weeks of treatment it was sufficient for evaluation. To determine whether there is any significant difference in the average value there needs to be a " $t$ " test. Results of these tests are presented in Table I.
TABLE I: Test Result SCORING DifFEREnCE OF PRE TEST AND POSt TeST

\begin{tabular}{|c|c|c|c|c|c|}
\hline \multicolumn{6}{|c|}{$\begin{array}{l}\text { FOR STATISTICS } \\
\end{array}$} \\
\hline \multirow{2}{*}{$\begin{array}{l}\text { Materia } \\
\text { l Aspect }\end{array}$} & & Pre test & Post test & Gain & $\%$ \\
\hline & $\begin{array}{r}\mathbf{M} \\
\mathbf{n} \\
\end{array}$ & Max MeanSD & Min MaxMean SD & score & score \\
\hline & 4247 & $80 \quad 61,43$ & $87 \quad 69,4$ & 8,05 & 13 \\
\hline
\end{tabular}

Results of the analysis in Table I show the magnitude of the mean difference before and after the development of an algo-heuristic model of statistical material. The analysis shows an average pre-test score of 61.43 and an average post-test score of 69.48 with a difference of 8.05 and a relative increase of $13.1 \%$. Differences in the values of these scores indicate a significant increase with an upward trend. $\mathrm{T}$ test analysis results equal -5.111 with a probability of 0.000 . These results indicate that the algo-heuristic model development for students in statistics courses should be implemented.

\section{DISCUSSION ON RESEARCH FINDINGS}

Based on the results of the development of algo-heuristic research with a focus on product development is learning of algo-heuristic of the syntax, learning guide, and student worksheets. The following discussion will explain how the three supplements that learning has an important position in implementation of the algo-heuristic learning. Algo-heuristic will be integrated with a statistics course. The next step in learning the syntax is doing the learning developed as the realization of a theoretical study conducted run private individuals.

Creation which is based on an understanding of learning syntax according [1] Santyasa (2007) will facilitate the implementation of learning by other teachers or by learners themselves, because the syntax based learning as operational measures described by the theory of instructional design. Understand syntax based constructivist learning often were adapted according to the needs. It becomes important to enhance the recursive syntax, flexible, and dynamic. It is interesting to study that syntax algo-heuristic which has developed high expectations in shaping students' positive attitudes such as: motivation to learn, learning independence. Syntax developed heuristic algo-conditioned students with high- level thinking activities. Students learn to use innovative thoughts and creative in analyzing statistics. Guidelines for the design of algo-heuristic arethe most effective if it is really able to run and be able to deliver messages targeted to faculty and students.

In this case the product is user-heuristic algo guidelines. For this purpose, the algo-heuristic design guides are designed with a simple format and language that are practical and easily understood by users (faculty and students). Student Worksheet (MFI), which was designed by the researcher really well when done by students, will provide opportunities to learn independently and spawned a good problem-solving skills. About the items presented in the MFI-based algo-heuristic is developed based on the principles of constructivist learning, which views learners as subjects who were able to reconstruct their learning. Through MFIs, students can develop independent learning culture and learn to solve real problems. Application of algo-heuristic has 
shown that such an approach could make students experience significant learning process, learning is developed based on the ideology of constructivism. Learners are given the opportunity to explore their own information through reading various books directly, make presentations to other people, communicate the results of their activities to others, work in groups, giving suggestions or ideas for other people and a variety of other activities. Describes everything about how adults should learn to be more meaningful. [8] Hembree and Marsh (1994) which states that the procedure algorithmic establish rules and procedures to guide the learner's problem solving find a solution. [15] Hutchinson, et al (2005) proved that mathematically, the decision taken by the heuristic thinking patterns so that decisions are effective. In humans algorithmic approach is the basis for managing the process of thinking that spawned sort cognitive capabilities.

The ability to adapt to the environment based on a rationalistic thinking using mathematical calculations based on heuristic thinking. [14] Ballarin (2004) showed limited programming using algebraic system can be applied for parametric systems of linear equations. According to the version of Gaussian calculations algorithmic computing, computational calculations and completion of parametric determination, it can be used as the basis for determining the parametric linear. [4] Landa (1999) states that the greater the difference/ discrepancies between the number of variations is objectively necessary and the amount of actual variations available, the greater the likelihood that, (a) the generalization that formed in the minds of learners would be unsuitable and as a result, (b) the average level of concept of inaccurate based on the generalization would be very high. [4] Landa (1999) made their formation into a formation of well-planned and well- organized learning process, thus guaranteeing the high quality of the development of mental abilities as a result of a collaboration.

[7] Landa (1983) a process consisting of a series of relatively basic operations shown in regular and uniform manner in a condition that provides an explanation for solve the problems of a particular class is an algorithmic process. [7] Landa (1983) states this algorithmic designed and used more particularly in the field of mathematics.

\section{CONCLUSIONS}

Free teaching materials have met the acceptance criteria of statistics, covering aspects: usability, accuracy and feasibility. Based on expert judgment and expert instructional design courses provide statistics on the aspects of usability with a high score, the average score given by the two experts to achieve a total score of 26 . Based on the feasibility aspect the two experts give a high enough score, the cumulative rate of the average score given by the two experts reached a total score of 31 .

Based on aspects of precision, both experts provide statistical assessment of instructional materials with a high enough score, the average total score of 32. Algo-heuristic model of product delivery including but not limited teaching materials developed in the form of books, have meet the criteria of effectiveness. Statistics score shows a difference and there is a significant increase. This indicates adequate statistical learning to be implemented.

\section{RECOMMENDATION}

Learning Outcomes - Algo-heuristic learning strategies can be used to obtain better learning achievement. The learning strategy can be implemented by faculty who has taught courses in statistics. As for ways to develop an efficient algorithm: 1) identify by diagnostic analysis the target population, 2) make all learning a step in the algorithm and make it understandable so that it does not cause confusion in the learners, 3) make it a complete range of learning, 4) make all learning appear as common so that the algorithm is as general as possible, 5) make the learning impart logical and natural reasons, and 6) create an economically efficient learning structure. Present algo-heuristic processes in a step-by-step fashion that provides an explanation after each step has been mastered. Based on this lecturers should choose this model for learners in statistics courses.

Learning strategies in this model demand activity and independence on the part of students. In this regard, both of those conditions should be developed in students so that the algo-heuristic model can run smoothly according to the lesson plans.

\section{ACKNOWLEDGMENT}

Rufi'i would like to thank for those who contributed to the completion of the paper; Directorate of Higher Education, Ministry of Education and Culture of Indonesia for the research funding and University PGRI Adi Buana Surabaya for data providing.

\section{REFERENCES}

[1] I. K. Davies, Instruction Technique, New York: McGraw Hill Book Company, 1984.

[2] C. M. Charles, Individualizing Instruction ( $\left.2^{\text {nd }} e d\right)$, St.Louis, Missouri: The CV Mosby Company, 1980.

[3] L. N. Landa, "A fragment of a lesson based on thealgo-heuristic theory of instruction," in Instructional Theories in Action: Lessons Illustrating Selected Theories and Models, C. M. Reigeluth, (Editor), Hillsdale: Lawrence Erlbaum Associates, 1987.

[4] L. N. Landa, "Landamatics instructional-design theory and methodology for teaching general methods of thinking," in Instructional-Design Theories and Models: A New Paradigm of Instructional Theory, Volume II, C. M. Reigeluth, (Editor), Mahwah: Lawrence Erlbaum Associates, Publishers, 1999.

[5] L. N. Landa, Agorithmization in Learning and Instruction, Englewood Cliffs: Educational Technology Publications, 1974.

[6] L. N. Landa, Instructional Regulation and Control, Englewood Cliffs: Educational Technology Publications, 1976.

[7] L. N. Landa, "The Algo-Hueristic Theory of Instruction," Instructional-Design Theories and Models: An Overview of Their Current Status, C. M. Reigeluth, Eds., Hillsdale: Lawrence Erlbaum Associates, Publishers, 1983.

[8] R. Hembree and H. dan Marsh, "Problem solving in early childhood building foundation," Research Ideas for the Classroom: Early Childhood Mathematics, R. J. Jehnsen Eds., New York: Macmilan Publishing Company, 1994.

[9] Gumadi, K. R. Gumadi, S. Gribble, S. Ratnasamy, S. Shenker, and I. Stoica, The Impact of DHT Routing Geometry on Resilience and Proximity, SIGCOMM'03, 381-394, 2003.

[10] K. Fabian, R. Wattenhofer, A. Zollinger, Worst-Case Optimal and Average-Case Efficient Geometric Ad-Hoc Routing, MobiHoc'03, pp. 267-278, 2003.

[11] C. H. Jagadish and H. V. L. dan Pitt, "Optimal indexing using near-minimal space," PODS, pp. 244-251, 2003.

[12] C. Rada and C. Li, "Materializing views with minimal size to answer queries," PODS, pp. 38-48, 2003.

[13] C. Mario, J.-P. Hubaux, and C. Enz. (October 17, 2008). Minimum-Energy Broadcast in All-Wireless Networks: NP-Completeness and Distribution Issues. MOBICOM'02, 2004 
[Online $]$.

Available: http:www.simobile.orgmobilecom2002paperp044-cagalj.pdfseacrhter $\mathrm{m}=$ algo+heuristics

[14] B. Clemens, "Solving parametric linear systems: an experiment with constraint algebraic programming," ACM SIGSAM Bulletin, vol. 38, no. 2, pp. 33-46, 2004.

[15] J. M. C. Hutchinson and G. Gerd, "Simple heuristics and rules of thumb: where psychologists and behavioural biologists might meet," Behavioural Processes, vol. 69, pp. 97-124, 2005.

[16] L. Jeremi, T. Friedman, and V. Conan, (October 17, 2008). DTN Routing in a Mobility Pattern Space. SIGCOMM'05 Workshops, 2005. [Online]. Available: http://www.sigcomm.orgco-next2005paper-LegFri.pdfsearchterm=alg o+heuristics

[17] S. Bassem, D. V. Gucht, and P. W. Purdom, "On the effectiveness and eficiency of computing bounds on the support of item-sets in the frequent item-sets mining problem," OSDM'05, pp. 46-55, 2005.

[18] Y. M. Heong, W. Othman, J. M. Yunos, T. T. Kiong, R. Hassan, and M. M. Mohamad. (2011). The level of marzano higher order thinking skills among technical education students. International Journal of Social Science and Humanity. [Online]. 1(2). pp. 121-125. Available: http//ijssh.org

[19] Rufi'i, Pengaruh Strategi Pembelajaran dan Gaya Kognitif terhadap Perolehan Belajar Konsep dan Prosedur Statistika, Unpublished dissertation, Malang: Instructional Technology Study Program, Program Graduate, State Universitas of Malang, 2010.

[20] D. Walter and C. Lou, The Systematic Design of Instruction, Fifth Edition, Longman. Addison-Wesley Educational Publisher, New York, 2001.

[21] R. I. Arends, Classroom Instruction and Managements, New York: Mc Grawhill Companies, Inc, 1997.

[22] C. M. Reigeluth and M. D. dan Merrill, "Classes of instructional variables," Educational Technology, vol. 19, no. 3, pp. 5-24, 1979.
[23] I. W. Santyasa, "Model-model pembelajaran inovatif paper," presented in training on Classroom Action Research for teachers junior and senior high schools in Nusa Penida, June 29-July 1, 2007.

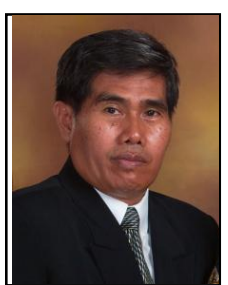

Rufi'i was born in Surabaya, Indonesia. His secondary education was completed in 1982. He pursued further education at the Department of Technical Building Education of State Teacher Training Institute Surabaya with a scholarship of Improving Academic Achievement to be completed in 1987. In 1992 he continued his education at master level courses in educational research and evaluation commission. $\mathrm{He}$ earned his master of education in 1995 . He also took undergraduate program in statistics and graduated in 2000. Then he studied civil engineering education and graduated in 2003. In 2007 he continued his education at the doctoral level in instructional technology graduate study program, State University of Malang. He had the opportunity to follow the sandwich course at the University of Queensland Brisbane Australia, and obtained his $\mathrm{PhD}$ in 2010.

He has teaching experience at the University of PGRI Adi Buana Surabaya started as the secretary of the department in 1987 to 1992. Then as the head of the academic in 1996, the head of Bureau of Academic and Students Affairs Administration to 1998, and secretary of the Institute of Research from 1998 to 2007. As the chairman of the education and training of distance education from 2011 to 2015. While positions in teache education and professional training began in 2011 as the chairman of division, then in 2012 as chief executive, in 2013 as chairman of the division. He has been a lecturer since 1987 up to now.

Rufi'I has been assigned as the head of the study program in Educational Technology Graduate University of PGRI Adi Buana Surabaya in 2013. His research interests are statistical research, research methodology, and evaluation of education. 